\title{
Modification of the Highway Capacity Manual two-lane highway analysis procedure for Spanish conditions
}

\author{
Ana T. Moreno ${ }^{1}$, Carlos Llorca ${ }^{1}$, Scott S. Washburn ${ }^{2}$, José E. Bessa ${ }^{3}$, \\ David K. Hale ${ }^{4}$ and Alfredo Garcia ${ }^{5}$ \\ ${ }^{1}$ Department of Civil, Geo and Environmental Engineering, Technical University of Munich, Arcisstr. 21, 80333 Munich, \\ Germany \\ ${ }^{2}$ Department of Civil and Coastal Engineering, University of Florida, Gainesville, FL, U.S.A. \\ ${ }^{3}$ Federal Center for Technological Education of Minas Gerais, Belo Horizonte, Brazil \\ ${ }^{4}$ Leidos, Inc., Reston, VA, U.S.A. \\ ${ }^{5} H E R G$, Universitat Politècnica de València, Valencia, Spain
}

\begin{abstract}
SUMMARY
The US Highway Capacity Manual (HCM) methodology is used in Spain to evaluate traffic operation and quality of service. The effect of passing manoeuvre on two-lane highway operational performance is considered through adjustment factors to average travel speeds and percent time spent following. The procedure is largely based on simulations in TWOPAS and passing behaviours observed during US calibrations in the 1970s. It is not clear whether US driving behaviour and vehicles' performance are comparable with Spanish conditions. The objective of this research is to adapt the HCM 2010 methodology to Spanish driver behaviour, for base conditions (i.e. no passing restrictions). To do so, TWOPAS was calibrated and validated based on current Spanish passing field data. The calibration used a genetic algorithm. The case study included an ideal two-lane highway with varying directional traffic flow rate, directional split and percentage of trucks. The updated methodology for base conditions is simpler than the current HCM 2010 and does not rely on interpolation from tables. Copyright (C) 2016 John Wiley \& Sons, Ltd.
\end{abstract}

KEY WORDS: traffic operation; two-lane highway; percent time spent following; average speed; percent followers; genetic algorithm

\section{INTRODUCTION}

Two-lane highways have a level of interaction between vehicles traveling in the same direction and in the opposing direction, which results in unique operational characteristics, mainly because faster vehicles wishing to travel at their desired speed must use the oncoming lane to pass slower vehicles (where a passing lane is not present). Moderate-to-high traffic demands in the opposing direction can greatly restrict passing opportunities and usually decrease the perceived level of service.

In order to analyse level of service, Spanish standards [1] rely on the procedures of the US Highway Capacity Manual (HCM) [2]. Given the differences in road environment, driving behaviour and vehicles' performance, the HCM procedure would not be completely suitable for application to Spanish conditions. Therefore, there is a need to document current passing behaviour in Spain and relate it to traffic performance. Unfortunately, field measurements can be expensive, and most importantly, they rarely provide sufficient repeatability for the full range of traffic demands; so, the conclusions may only be applicable to the observed conditions. At this point, traffic microsimulation must be considered.

*Correspondence to: Ana T. Moreno, Department of Civil, Geo and Environmental Engineering, Technical University of Munich, Arcisstr. 21, 80333 Munich, Germany. E-mail: ana.moreno@tum.de 
The objective of this paper is to modify the HCM two-lane highway analysis procedure for Spanish conditions. This approach would add fidelity to operational analyses of Spanish two-lane highways. Only base conditions (i.e. no passing restrictions) were analysed in this research. The analysis of passing restriction effects will be provided in a future publication.

The organization of the paper is as follows. Section 2 reviews research related to two-lane highway traffic performance. Section 3 presents the simulation data and model development methodology. Results and analyses are discussed in Section 4. Finally, a summary of the main findings and conclusions are in Section 5.

\section{LITERATURE REVIEW}

Operational analyses of Spanish two-lane highways rely on the procedures of the US HCM [2]. For twolane highways, level of service is based on up to three performance measures, depending on highway classification: average travel speed (ATS), percent time spent following (PTSF) and percent free flow speed. Given the difficulties of measuring PTSF in the field, the HCM suggests that percent followers (PFs) can be used as a surrogate for PTSF. Further, the HCM recommends a 3-s headway threshold to determine whether a vehicle is following, because this value was found to minimize differences between PTSF and PF [3]. The HCM procedure estimates traffic performance for the base scenario (i.e. passing is allowed along the entire length of the segment), adjusting traffic demands to account for truck and grade impacts. ATS has a linear relationship with directional and opposing traffic flow (Table I), while PTSF varies exponentially with directional traffic flow (Table II). Then, passing restriction effects are considered through adjustment factors to the performance measures. These adjustments are based in large part on simulation results from the microsimulation program TWOPAS [3, 4].

TWOPAS was originally developed by the Midwest Research Institute between 1971 and 1974 and had occasional updates through the late 1990s [5]. TWOPAS currently is packaged with the Traffic Analysis Module of the Interactive Highway Safety Design Model from the Federal Highway Administration. Horizontal and vertical alignment can be included and affect the desired speed. To develop the HCM procedure, field data collected in the 1990s were used to calibrate TWOPAS results on ATS and PTSF, although passing behaviour was not updated [3]. No indications of the calibration method, precision of the adjustment or how passing zones were distributed were given [6]. In TWOPAS, PTSF is calculated as the proportion of the time in which drivers are in states different than the state 'free vehicle, unimpeded by other': overtaking a leader, following a leader, close following with interest and capability of passing, passing another vehicle or aborting a pass [5]. TWOPAS considers that a vehicle is a platoon member when the vehicle is traveling at a headway less than $4 \mathrm{~s}$ from its leader when it crosses the observation station [5]. This criterion to define free vehicles in TWOPAS

Table I. Literature review: ATS models for base conditions.

\begin{tabular}{|c|c|c|}
\hline Country & ATS or $\operatorname{ATS}_{\mathrm{pc}}$ & Reference \\
\hline USA & $A T S=F F S-0.0125 \cdot\left(V_{\mathrm{d}}+V_{\mathrm{o}}\right)$ & [2] \\
\hline Germany & $\begin{array}{ll}A T S_{\mathrm{pc}}=98.73-0.8176 \cdot \sqrt{V_{\mathrm{d}}} & (H V=0 \%) \\
A T S_{\mathrm{pc}}=100.40-1.0496 \cdot \sqrt{V_{\mathrm{d}}} & (H V=5 \%) \\
A T S_{\mathrm{pc}}=95.17-0.9554 \cdot \sqrt{V_{\mathrm{d}}} & (H V=10 \%) \\
A T S_{\mathrm{pc}}=94.42-1.0515 \cdot \sqrt{V_{\mathrm{d}}} & (H V=20 \%) \\
A T S_{\mathrm{pc}}=93.03-1.0712 \cdot \sqrt{V_{\mathrm{d}}} & (H V=30 \%)\end{array}$ & [9] \\
\hline Finland & $\begin{array}{l}A T S_{\mathrm{pc}}=F F S+b_{1} \cdot \sqrt{V_{\mathrm{d}}}+b_{2} \cdot V_{\mathrm{o}} \\
b_{1}=-0.166-0.00906 \cdot F F S+0.213 \cdot w_{\mathrm{L}} \\
b_{2}=0.015-0.000191 \cdot F F S\end{array}$ & [15] \\
\hline Brazil & $A T S=F F S-0.1398 \cdot \sqrt{V_{\mathrm{d}}}-0.1810 \cdot \sqrt{V_{\mathrm{o}}}$ & [16] \\
\hline Argentina & $A T S=F F S-0.013 \cdot V_{\mathrm{d}}-0.002 \cdot V_{\mathrm{o}}$ & [17] \\
\hline Egypt & $A T S=66.97-0.0172 \cdot V_{\mathrm{d}}-0.0154 \cdot V_{\mathrm{o}}$ & [20] \\
\hline Spain & $A T S=1 \cdot 10^{-8} \cdot V_{\mathrm{d}}^{3}-2 \cdot 10^{-5} \cdot V_{\mathrm{d}}^{2}+0.0027 \cdot V_{\mathrm{d}}+88.729$ & [24] \\
\hline Spain & $A T S=-1 \cdot 10^{-8} \cdot V_{\mathrm{d}}^{3}+2 \cdot 10^{-5} \cdot V_{\mathrm{d}}^{2}-0.0197 \cdot V_{\mathrm{d}}+75.426$ & [24] \\
\hline Spain & $A T S=129.265-6.03 \cdot \ln \left(V_{\mathrm{d}}\right)-0.314 \cdot H V$ & [25] \\
\hline India & $A T S=64.871-0.008 \cdot V_{\mathrm{t}}$ & [26] \\
\hline
\end{tabular}


Table II. Literature review: PTSF models for base conditions.

\begin{tabular}{llr}
\hline Country & & \multicolumn{1}{c}{ PTSF or PF } \\
\hline USA & PTSF $=100 \cdot\left(1-\exp \left(a \cdot V_{\mathrm{d}}^{\mathrm{b}}\right)\right)$ & {$[2]$} \\
Finland & $P T S F=1-\exp \left(b_{1} \cdot \frac{V_{\mathrm{d}}}{3600}+b_{2} \cdot \sqrt{\frac{V_{\mathrm{o}}}{3600}}\right)$ & {$[14]$} \\
& $b_{1}=4.118$ & \\
& $b_{2}=-0.439+0.093 \cdot w_{\mathrm{L}}$ & {$[16]$} \\
Brazil & $\mathrm{PTSF}=100 \cdot\left(1-\exp \left(a \cdot V_{\mathrm{d}}^{\mathrm{b}}\right)\right)$ & {$[17]$} \\
Argentina & $P T S F=V_{\mathrm{d}}^{\mathrm{a}} \cdot \exp \left(b-c \cdot V_{\mathrm{d}}\right)$ & {$[23]$} \\
Spain & $P F_{4} \mathrm{sec}=25.5411+0.0443 \cdot V_{\mathrm{d}}+0.0096 \cdot V_{\mathrm{o}}$ & {$[18]$} \\
USA & $P F=0.0578 \cdot V_{\mathrm{d}}+0.0080 \cdot V_{\mathrm{o}}+1.4849 \cdot H V$ & {$[18]$} \\
USA & $P F=0.0338 \cdot V_{\mathrm{d}}+0.0061 \cdot V_{\mathrm{o}}-0.1606 \cdot H V+2.1274 \cdot \sigma_{\mathrm{FFS}}$ & {$[21]$} \\
Israel & $P T S F=100 \cdot\left(1-\exp \left(-0.00504 \cdot V_{\mathrm{d}}\right)\right)$ & {$[20]$} \\
Egypt & $P F=0.091+0.00058 \cdot V_{\mathrm{d}}+0.00007 \cdot V_{\mathrm{o}}$ & {$[22]$} \\
Israel & $P T S F=100 \cdot\left(1-\exp \left(-0.00401 \cdot V_{\mathrm{d}}\right)\right)$ & {$[25]$} \\
Spain & $P F=-60.6933+24.4293 \cdot \ln \left(V_{\mathrm{d}}\right)$ & {$[26]$} \\
India & $P F \mathrm{bi}=9.463+0.026 \cdot V_{\mathrm{t}}$ & \\
\hline
\end{tabular}

$a$ and $b$ are interpolated depending on $V_{\mathrm{o}}$.

is different from the 5-s criteria used to define percent time delay in the HCM 1985 [7] and the 3-s criteria used to define PFs in the HCM 2000 and 2010 [2, 8]. Despite differences between the definition of PTSF in the HCM and its calculation in TWOPAS, this output parameter was used to develop the $\mathrm{HCM}$ analysis procedure.

Germany has its own methodology to analyse traffic operations, reported in the Handbuch für die Bemessung von Strassenverkehrsanlagen (HBS) [9]. For two-lane highways, level of service is based solely on density, defined as the ratio between directional traffic flow and average passenger car travel speed $\left(\mathrm{ATS}_{\mathrm{pc}}\right)$. PTSF has never been considered as a substantial performance measure in Germany. This is because the generation of platoons is considered a consequence of two-lane traffic and does not directly express the degree of traffic operational efficiency [10]. For each combination of truck percentage category, horizontal alignment class and vertical alignment class, ATS $_{\mathrm{pc}}$ is directly obtained from the speed-flow relationship. These relationships are based on simulation results from the microsimulation program LASI [11]. The shape of the speed-flow curve is generally concave (Table I). Truck percentage is categorized into five categories: 0, 5, 10, 20 and 30\%. Horizontal alignment class depends on 'bendiness' of the highway, while vertical alignment class depends on the most restrictive highway upgrade. Passing restrictions are not considered as they showed a marginal effect on traffic performance, and directional split is not included for purely directional analyses [11]. LASI was manually calibrated by using field data from 14 sites [12] and validated with an additional of four sites [11]. Passing behaviour has not been updated since the initial version of LASI [13]. LASI is not publicly distributed.

In Finland, the performance measures for two-lane highways are PTSF and ATS of passenger cars $[14,15]$. Traffic flow data were collected from 20 sites. ATS $\mathrm{pc}_{\mathrm{c}}$ and PTSF were modelled from the field data. The speed-flow curve is concave (Table I). For PTSF, the relationship with directional and opposing traffic flow is exponential. However, the square root of opposing flow rate is used because the marginal effect of opposing flow rate decreases at high opposing flow rates (Table II). Both ATS $_{\mathrm{pc}}$ and PTSF can be easily calculated by using equations, without interpolation from tables.

Researchers from Brazil [16] and Argentina [17] have proposed local modifications of the US HCM for two-lane highways. Field data were collected from 11 locations to adapt the 2000 HCM to Brazilian conditions [16]. They calibrated and validated TWOPAS by using a genetic algorithm. A concave in shape speed-flow relationship was proposed, as in the HBS. The HCM exponential function for PTSF is maintained, as well as adjustment factors based on opposing flow. Passing behaviour was not modified from the original TWOPAS calibration, and they proposed the same adjustments for passing restrictions as in the HCM. CORSIM was used to adapt the HCM to Argentinian conditions [17]. CORSIM was manually calibrated by using field data (three sites, $1 \mathrm{~h}$ per site). A linear function for ATS and an exponential function for PTSF were proposed. Similar to Brazil, adjustments for passing restrictions are the same as in the HCM, and coefficients for the PTSF exponential function are interpolated from tables. 
Some authors have calibrated traffic performance measures by using field data in Montana [18-20], Egypt [20], Israel [21, 22], Spain [23-25] and India [26]. Different performance measures were considered in the studies, although they usually included ATS and PF as a surrogate for PTSF. Researchers proposed linear relationships between directional traffic flow and PF (Table II). The PF flow rate follows an exponential form but for lower to moderate flow rates; as likely observed in the field, a linear relationship may provide a reasonable fit and is of course simpler to apply. However, a linear relationship cannot capture the rapid PF increase for directional traffic flows beyond $400-500 \mathrm{veh} / \mathrm{h}$ and deviates significantly from simulation studies in its estimations for higher traffic flow rates. PF was calculated by using the 3-s threshold recommended in the HCM, except in two studies $[23,26]$ that used 4 and $2.6 \mathrm{~s}$ respectively. A theoretical approach was used to calculate PTSF based on the number of gaps inside and outside platoons [21,22]. The main assumptions of this approach were that (i) all drivers are willing to pass when their actual speed falls below their desired speed and (ii) that the first vehicle to arrive to a queue is the first to pass. This approach provided good estimates for Israeli data but produced lower PTSF estimates than the HCM.

To sum up, the USA, Germany, and Finland developed their own analysis procedure to evaluate traffic performance in two-lane highways, while the US analysis procedure was adapted to Brazil and Argentina through TWOPAS and CORSIM microsimulations. Performance measures differ in Germany (density using ATS $_{\mathrm{pc}}$ ) and Finland $\left(\mathrm{ATS}_{\mathrm{pc}}\right.$ ), while PTSF and ATS are preferred in the USA, Brazil and Argentina. Even though ATS and PTSF are estimated in practically all studies, each research study adapted the functional form to their results. While microsimulation studies propose a convex functional form (concave in shape) for ATS and exponential form for PTSF, field studies propose linear relationships for both ATS and PTSF. A summary of the equations for ATS and PTSF estimation is provided in Tables I and II respectively.

\section{DATA AND METHODOLOGY}

This study is based on microsimulation results from the TWOPAS program. TWOPAS was selected because it was previously used to develop the HCM analysis procedure and it was the only program available at the time of the research that was calibrated by using field data. The program was calibrated with field data collected across Spanish two-lane highways. The methodology is as follows:

- To document current passing behaviour on Spanish two-lane highways.

- To calibrate and validate TWOPAS by using a genetic algorithm. Passing behaviour will also be calibrated, as passing rate was included within the fitness function.

- To generate and simulate multiple scenarios in TWOPAS with varying directional traffic flow, directional split and truck percentage.

- To model ATS and PTSF for the base conditions (i.e. no passing restrictions).

The description of each task is provided in the following sections.

\subsection{Field data}

Data were collected across four passing zones located along the two-lane highway N-225 in Spain. Passing zones are defined as the part of the highway where passing is permited on thel direction of analysis. The highway served as a primary connector between two freeways, and therefore was classified as a class I two-lane highway. Characteristics of the passing zones are summarized in Table III. A total of $52 \mathrm{~h}$ of video data were collected on N-225. Data were collected during daytime hours under good weather conditions and with the pavement in good condition.

Video recordings were used at the beginning and end of each passing zone. The videos were individually analysed to obtain time stamps for each vehicle in both locations. Directional traffic flow, traffic composition, average travel time and time headway were obtained. Individual time headways were calculated at the beginning and end of each passing zone. Then, ATS was calculated as the ratio between passing zone length and difference in time stamps. PFs were calculated by using the HCMrecommended 3-s headway threshold. The number of passing manoeuvres was calculated by comparing vehicles' order at the beginning and end of the passing zone. Variations in order indicated 
Table III. Characteristics of the passing zones from N-225.

\begin{tabular}{|c|c|c|c|c|c|c|c|}
\hline ID & Highway & Station $(\mathrm{m})$ & Bound & $\begin{array}{l}\text { Passing zone } \\
\text { length }(\mathrm{m})\end{array}$ & $\begin{array}{c}\text { Two-way traffic } \\
\text { flow (veh/h) }\end{array}$ & $\begin{array}{l}\text { Number of } \\
\text { passes }\end{array}$ & Duration (h) \\
\hline 1 & $\mathrm{~N}-225$ & 5500 & 1 & 265 & \multirow[t]{5}{*}{$120-900$} & 148 & \multirow[t]{4}{*}{$13: 00$} \\
\hline 2 & & & 2 & 507 & & 279 & \\
\hline 3 & & 6100 & 1 & 1270 & & 680 & \\
\hline \multirow[t]{2}{*}{4} & & & 2 & 1050 & & 542 & \\
\hline & & & & & & 1649 & $52: 00$ \\
\hline
\end{tabular}

the performance of passing manoeuvres. When the same vehicle made two or more position changes, this was classified as a multiple-passing manoeuvre.

The results were aggregated into 15 -min periods as the sum of three consecutive 5 -min periods (i.e. $0-15,5-20,10-25$, etc.). Consequently, the possible error of not identifying the peak 15-min period in two consecutive 15-min counting periods was avoided [27]. Equivalent hourly data were then calculated based on the 15-min data. For each counting period, the following measures were obtained: directional traffic flow, traffic composition, ATS, speed distribution of passenger cars, speed distribution of trucks, number of passes and PFs at the beginning and end of passing zones.

Passing behaviour on N-225 was validated with observations from 12 additional passing zones in Spain [28]. Selection criteria for the additional passing zones included two-way traffic flow range, directional split, traffic composition and passing zone length (Table IV). For the validation of passing behaviour, $46 \mathrm{~h}$ were collected in additional passing zones. The data were previously used to model the number of passing manoeuvres [28] and to calibrate alternative performance measures [25].

\subsection{Calibration scenarios in TWOPAS}

Horizontal and vertical alignments across N-225 were obtained by using GPS tracks with $10 \mathrm{~Hz}$ frequency. The highway had two crest vertical curves and one sag vertical curve. The horizontal alingment was straight, with one long tangent. Cross section $(3.5 \mathrm{~m}$ lane width and $1.5 \mathrm{~m}$ shoulder width), available sight distance, no-passing zones and posted speed limit $(100 \mathrm{~km} / \mathrm{h})$ were also characterized. Available sight distance was manually calculated based on video recordings from vehicles and Google Earth aerial view. TWOPAS default values of driver's eye height $(1.07 \mathrm{~m})$ and object height $(1.07 \mathrm{~m})$ were adapted to Spanish conditions (i.e. 1.10 and $1.10 \mathrm{~m}$ ) to calculate passing sight distance.

Seven of the 13 available vehicle types in TWOPAS were used: five passenger cars (subcompact car, compact car, midsize car, van and sport utility vehicle) and two trucks (two axles). For passenger cars, maximum acceleration and overall length were adjusted to the most representative vehicle for

Table IV. Validation of passing behaviour: characteristics of the passing zones.

\begin{tabular}{|c|c|c|c|c|c|c|c|}
\hline ID & Highway & Station (m) & Bound & $\begin{array}{l}\text { Passing zone } \\
\text { length }(\mathrm{m})\end{array}$ & $\begin{array}{l}\text { Two-way traffic } \\
\text { flow (veh/h) }\end{array}$ & $\begin{array}{c}\text { Number of } \\
\text { passes }\end{array}$ & Duration (h) \\
\hline 1 & \multirow[t]{4}{*}{ CV -50} & \multirow[t]{2}{*}{84500} & 1 & 600 & \multirow[t]{2}{*}{$215-365$} & 52 & \multirow[t]{2}{*}{ 4:00 } \\
\hline 2 & & & 2 & 850 & & 43 & \\
\hline 3 & & \multirow[t]{2}{*}{77500} & 1 & 990 & \multirow[t]{2}{*}{$175-420$} & 15 & \multirow[t]{2}{*}{$2: 50$} \\
\hline 4 & & & 2 & 755 & & 10 & \\
\hline 5 & \multirow[t]{2}{*}{ CV -37} & \multirow[t]{2}{*}{14000} & 1 & 550 & \multirow[t]{2}{*}{$180-375$} & 25 & \multirow[t]{2}{*}{$3: 00$} \\
\hline 6 & & & 2 & 560 & & 31 & \\
\hline 7 & \multirow[t]{4}{*}{$\mathrm{CV}-35$} & \multirow[t]{2}{*}{76000} & 1 & 540 & \multirow[t]{2}{*}{$100-150$} & 5 & \multirow[t]{2}{*}{$5: 55$} \\
\hline 8 & & & 2 & 522 & & 11 & \\
\hline 9 & & \multirow[t]{2}{*}{44500} & 1 & 1130 & \multirow[t]{2}{*}{$180-305$} & 58 & \multirow[t]{2}{*}{$4: 05$} \\
\hline 10 & & & 2 & 1265 & & 48 & \\
\hline 11 & \multirow[t]{2}{*}{$C V-25$} & \multirow[t]{2}{*}{5000} & 1 & 1000 & \multirow[t]{3}{*}{$310-1100$} & 17 & \multirow[t]{2}{*}{$3: 20$} \\
\hline 12 & & & 2 & 1000 & & 62 & \\
\hline \multicolumn{5}{|c|}{ Total for validation of passing behaviour } & & 377 & $46: 20$ \\
\hline
\end{tabular}


each vehicle type (Renault Clio, Renaul Megane, Ford Mondeo, Peugeot Partner and Nissan Terrano). Similarly, weight/net horsepower ratio, weight/projected frontal area ratio and overall length were adjusted for the two truck types (Scania P $2704 \times 2$ and Volvo FH tractor). The percentage of each vehicle type was assigned based on the observations.

Mean desired speed and standard deviation were estimated based on the unimpeded speed distributions. A headway value longer than $6 \mathrm{~s}$ was considered as the criterion to determine unimpeded speeds, based on the analysis of speeds from field data. This threshold was also suggested based on empirical observations [29].

For the calibration, 30 non-overlapped counting periods (i.e. counting periods 0 to $15 \mathrm{~min}, 15$ to $30 \mathrm{~min}$, etc.) for the four passing zones were used. The 60 remaining periods were left for validation (i.e. counting periods from 5 to $20 \mathrm{~min}, 10$ to $25 \mathrm{~min}, 20$ to $35 \mathrm{~min}$, etc.).

\subsection{Calibration and validation of TWOPAS with genetic algorithm}

The goal of calibration was to find a combination of parameters that would minimize differences between simulated and field-collected ATS, PF and passing rate. Direct brute force searching was used as a first approach, but the number of combinations required excessive computational times. For this research, the genetic algorithm proposed by Bessa and Setti [16] was utilized for the calibration of TWOPAS.

Calibration parameters, fitness function, genetic parameters and stopping criteria were adapted to the observed data. Calibration parameters must be adjustable by users and represent driver behaviour. Among the possible parameters, 12 were included:

- Passing reconsider probability: probability that simulation driver will reconsider starting a pass during one review period. The default value is 0.2 .

- Car following factor (ZKCOR): proportionality constant used in calibrating the car following model. The default value is 0.8 .

- Stochastic driver type factors (BKMP1 to BKMP10): 10 multiplicative parameters from a stochastic distribution of time headways used in car following. It defines the risk-taking characteristics of each of 10 driver types. The default values range from 0.43 to $2.12 \mathrm{~s}$.

The genetic algorithm's objective was to minimize the fitness function. This function was defined as the mean average square error between the simulated results and field data [Equation (1)]. It depended on 20 parameters (10 per direction):

$$
F=\frac{1}{M} \cdot \sum_{i=1}^{M} \sum_{j=1}^{N} \sum_{k=1}^{K} w_{\mathrm{k}} \cdot\left|\frac{V_{\mathrm{OBS} \mathrm{ijk}}-V_{\mathrm{SIM} \mathrm{ijk}}}{V_{\mathrm{SIM} \mathrm{ijk}}}\right|
$$

where:

- $F$ : fitness function.

- $M$ : number of road segments.

- $N$ : number of demand periods.

- $K$ : number of parameters. They include (per travel direction) number of passes, PFs at the end of the segment (3-s headway criterion), average speed of passenger cars and trucks, standard deviation of speed of passenger cars and trucks, 15th percentile from speed distribution of passenger cars, 15th percentile from speed distribution of trucks, 85th percentile from speed distribution of passenger cars and 85th percentile from speed distribution of trucks.

- $W_{\mathrm{k}}$ : weight of the parameter.

- $V_{\mathrm{OBS}}$ : observed value.

- $V_{\text {SIM }}$ : simulated value.

Given that there were more speed-related variables than passing-related variables within the fitness function, assignment of equal weighting to all variables would likely produce suboptimal outcomes. Therefore, three combinations of weights were tested for the fitness function variables. The sensitivity analysis considered four generations for each combination. Ultimately, the combination that 
minimized the average error and individual variable error was weighted passes $86 \%$, PFs $6 \%$ and speeds $8 \%$.

The chosen genetic parameters were based on previous sensitivity analyses with 20 generations and 3 combinations of parameters. The best combination was mutation probability of 0.4 , predation probability of 0.3 and diversity (mutation and predation) every four generations. In other words, every four generations of the evolutive process, $30 \%$ of the worst individuals were eliminated from the population and replaced by new random individuals and $40 \%$ of all individuals were randomly mutated (i.e. some calibration parameter variables changed to new random values). Stopping criteria included maximum number of generations (80), minimum error threshold (3\%) or improvement error threshold (less than $1 \%$ in 15 generations). The genetic algorithm was executed for 80 generations of 40 individuals, 5 random seeds and 30 traffic scenarios. Thus, the total number of simulations was 480000 . Each simulation run was 15 min long, with a 15 -min warm-up period.

Minimum error was reduced from $7.9 \%$ (default values) to $3.8 \%$ (calibrated values). The error among the best 50 calibration parameter combinations was between 3.8 and $3.9 \%$. A sample of the 25 best combinations is summarized in Table V. Driving behaviour was more aggressive than the default in TWOPAS, as passing reconsideration probability was multiplied by 4 . The 25 best calibration parameter combinations were validated with additional field data (60 traffic scenarios). The average error was $4.3 \%$, very close to the calibration error compared with $7.9 \%$ for the default values.

\subsection{Case study scenarios}

The case study included an ideal 10-km long straight segment, without passing restrictions. The percent grade was $0.5 \%$. Traffic variables were varied as follows:

- Directional split: 20/80, 30/70, 40/60, 50/50, 60/40, 70/30 and 80/20.

- Directional traffic flow: between 100 and $1700 \mathrm{veh} / \mathrm{h}$ at $50 \mathrm{veh} / \mathrm{h}$ increments. Opposing traffic flow was calculated and limited to $1700 \mathrm{veh} / \mathrm{h}$ or two-way traffic flow of $3200 \mathrm{veh} / \mathrm{h}$.

- Percentage of heavy vehicles: 0, 10, 20 and $30 \%$.

Table V. TWOPAS 25 best combinations of calibration parameters.

\begin{tabular}{|c|c|c|c|c|c|c|c|c|c|c|c|c|}
\hline ID & PREC & ZCOR & BKPM1 & BKPM2 & ВKРM3 & BKPM4 & BKPM5 & BKPM6 & BKPM7 & BKPM8 & ВКРM9 & BKPM10 \\
\hline 1 & 0.55 & 0.88 & 1.84 & 0.26 & 1.35 & 1.79 & 1.78 & 1.75 & 1.91 & 1.79 & 1.74 & 1.44 \\
\hline 2 & 0.55 & 0.88 & 1.84 & 0.26 & 1.35 & 1.76 & 1.78 & 1.75 & 1.91 & 1.79 & 1.74 & 1.44 \\
\hline 3 & 0.55 & 0.88 & 1.84 & 0.26 & 1.35 & 1.82 & 1.78 & 1.75 & 1.91 & 1.79 & 1.74 & 1.44 \\
\hline 4 & 0.55 & 0.88 & 1.84 & 0.30 & 1.35 & 1.79 & 1.78 & 1.75 & 1.91 & 1.79 & 1.74 & 1.44 \\
\hline 5 & 0.55 & 0.88 & 1.84 & 0.26 & 1.40 & 1.79 & 1.78 & 1.75 & 1.91 & 1.79 & 1.76 & 1.44 \\
\hline 6 & 0.55 & 0.88 & 1.84 & 0.26 & 1.40 & 1.79 & 1.78 & 1.75 & 1.91 & 1.79 & 1.74 & 1.44 \\
\hline 7 & 0.55 & 0.88 & 1.84 & 0.26 & 1.35 & 1.79 & 1.78 & 1.75 & 1.91 & 1.79 & 1.74 & 1.40 \\
\hline 8 & 0.55 & 0.88 & 1.84 & 0.26 & 1.35 & 1.79 & 1.78 & 1.75 & 1.91 & 1.72 & 1.74 & 1.44 \\
\hline 9 & 0.98 & 0.88 & 1.77 & 0.26 & 1.40 & 1.79 & 1.78 & 1.75 & 1.91 & 1.79 & 1.74 & 1.44 \\
\hline 10 & 0.55 & 0.88 & 1.84 & 0.26 & 1.35 & 1.79 & 1.78 & 1.75 & 1.91 & 1.79 & 1.74 & 1.35 \\
\hline 11 & 0.55 & 0.88 & 1.84 & 0.26 & 1.35 & 1.79 & 1.78 & 1.75 & 1.91 & 1.71 & 1.74 & 1.44 \\
\hline 12 & 0.55 & 0.88 & 1.84 & 0.26 & 1.35 & 1.65 & 1.78 & 1.75 & 1.91 & 1.79 & 1.74 & 1.16 \\
\hline 13 & 0.58 & 0.88 & 1.84 & 0.26 & 1.40 & 1.79 & 1.78 & 1.75 & 1.91 & 1.93 & 1.74 & 1.44 \\
\hline 14 & 0.63 & 0.88 & 1.84 & 0.26 & 1.40 & 1.79 & 1.78 & 1.75 & 1.91 & 1.93 & 1.74 & 1.44 \\
\hline 15 & 0.58 & 0.88 & 1.84 & 0.26 & 1.40 & 1.79 & 1.78 & 1.75 & 1.91 & 1.93 & 1.74 & 1.44 \\
\hline 16 & 0.62 & 0.88 & 1.84 & 0.26 & 1.40 & 1.79 & 1.78 & 1.75 & 1.91 & 1.93 & 1.74 & 1.44 \\
\hline 17 & 0.58 & 0.88 & 1.84 & 0.26 & 1.40 & 1.79 & 1.78 & 1.75 & 1.91 & 1.93 & 1.74 & 1.44 \\
\hline 18 & 0.55 & 0.88 & 1.84 & 0.26 & 1.40 & 1.79 & 1.78 & 1.75 & 1.91 & 1.93 & 1.74 & 1.44 \\
\hline 19 & 0.58 & 0.88 & 1.84 & 0.26 & 1.40 & 1.79 & 1.78 & 1.75 & 1.91 & 1.93 & 1.74 & 1.44 \\
\hline 20 & 0.90 & 0.88 & 1.84 & 0.26 & 1.35 & 1.79 & 1.78 & 1.75 & 1.91 & 1.79 & 1.74 & 1.44 \\
\hline 21 & 0.55 & 0.88 & 1.84 & 0.26 & 1.40 & 1.79 & 1.78 & 1.75 & 1.91 & 1.93 & 1.74 & 1.44 \\
\hline 22 & 0.92 & 0.88 & 1.84 & 0.26 & 1.40 & 1.79 & 1.78 & 1.75 & 1.91 & 1.93 & 1.74 & 1.44 \\
\hline 23 & 0.91 & 0.88 & 1.84 & 0.26 & 1.40 & 1.79 & 1.78 & 1.75 & 1.91 & 1.93 & 1.74 & 1.44 \\
\hline 24 & 0.94 & 0.88 & 1.84 & 0.26 & 1.40 & 1.79 & 1.78 & 1.75 & 1.91 & 1.93 & 1.74 & 1.44 \\
\hline 25 & 0.86 & 0.88 & 1.84 & 0.26 & 1.40 & 1.79 & 1.78 & 1.75 & 1.91 & 1.93 & 1.74 & 1.44 \\
\hline
\end{tabular}

Note. PREC is the passing reconsider probability, ZCOR is the car following factor, and BKMP1 to BKMP10 are the stochastic driver-type factors. 
- Randomness: 15 replications. Random number seeds for entering headways, desired speeds and driving behaviour were selected among a sample of 25 , while the combination of calibration parameters was selected among the best 50 combinations of the calibration.

The total number of simulations was 9900 (19800 directional scenarios). The maximum directional traffic flow was $1540 \mathrm{veh} / \mathrm{h}$ (with $0 \%$ heavy vehicles), as higher traffic flows stalled TWOPAS. Therefore, the number of valid directional scenarios was reduced to 18975.

\subsection{Modelling ATS and PTSF}

Two performance measures were analysed: ATS and PTSF. PF was also calculated based on headway distributions at the end of the segment, using 3 and $4 \mathrm{~s}$ as the follower criterion (PF and PF4). The values were obtained from the TWOPAS output file (*.OUT).

Passenger car units from the HCM were not used. Instead, the effect of heavy vehicles was applied through the percentage of heavy vehicles, similar to the German procedure, but classified as a continuous variable.

In order to determine the most appropriate functional form for our local conditions, three functional forms were considered for ATS: the linear model from HCM and Maldonado et al. [2, 17] [Equation (2a)], the concave model from Luttinen [15] [Equation (2b)] and the concave model from HBS and Bessa and Setti $[9,16]$ [Equation (2c)].

$$
\begin{gathered}
A T S_{1}=F F S+a_{1} \cdot V_{\mathrm{d}}+b_{1} \cdot V_{\mathrm{o}}+c_{1} \cdot H V_{\mathrm{d}}+d_{1} \cdot V_{\mathrm{d}} \cdot V_{\mathrm{o}}+e_{1} \cdot V_{\mathrm{d}} \cdot H V_{\mathrm{d}} \\
A T S_{2}=F F S+a_{2} \cdot \sqrt{V_{\mathrm{d}}}+b_{2} \cdot V_{\mathrm{o}}+c_{2} \cdot H V_{\mathrm{d}}+d_{2} \cdot \sqrt{V_{\mathrm{d}}} \cdot V_{\mathrm{o}}+e_{2} \cdot \sqrt{V_{\mathrm{d}}} \cdot H V_{\mathrm{d}} \\
A T S_{3}=F F S+a_{3} \cdot \sqrt{V_{\mathrm{d}}}+b_{3} \cdot \sqrt{V_{\mathrm{o}}}+c_{3} \cdot H V_{\mathrm{d}}+d_{3} \cdot \sqrt{V_{\mathrm{d}}} \cdot \sqrt{V_{\mathrm{o}}}+e_{3} \cdot \sqrt{V_{\mathrm{d}}} \cdot H V_{\mathrm{d}}
\end{gathered}
$$

where:

- ATS is the average travel speed $(\mathrm{km} / \mathrm{h})$.

- FFS is the free-flow speed $(\mathrm{km} / \mathrm{h})$.

- $V_{\mathrm{d}}$ is the directional traffic flow rate $(\mathrm{veh} / \mathrm{h})$.

- $V_{\mathrm{o}}$ is the opposing traffic flow rate $(\mathrm{veh} / \mathrm{h})$.

- $H V_{\mathrm{d}}$ is the percentage of heavy vehicles $(\%)$.

- $a_{\mathrm{i}}, b_{\mathrm{i}}, c_{\mathrm{i}}, d_{\mathrm{i}}$ and $e_{\mathrm{i}}$ are coefficients.

For each model, all 32 possible combinations of five independent variables were executed in the $\mathrm{R}$ statistical software tool by using the MASS package [30]. Akaike information criteria (AIC), correlation between fitted values and simulation values, beta parameters, $p$-value of the variables and number of parameters were then used to determine the best model for ATS. A summary of the goodness of fit of the 32 models is provided on the supporting information, as well as a statistical summary of the best model. Then, the best model estimates were compared with the estimates from previous models on the literature.

Similarly, four model functional forms were considered to define the most appropriate model for PTSF: the exponential model from HCM and Bessa and Setti $[2,16]$ [Equation (3a)], the exponential model from Maldonado et al. [17] [Equation (3b)], the exponential model from Luttinen [14] [Equation (3c)] and the logarithmic model from Moreno et al. [25] [Equation (3d)].

$$
\begin{gathered}
P T S F_{1}=100 \cdot\left(1-\exp \left(a_{1} \cdot V_{\mathrm{d}}{ }^{\mathrm{b}_{1}}\right)\right. \\
P T S F_{2}=V_{\mathrm{d}}^{\mathrm{a}_{2}} \cdot \exp \left(b_{2}-c_{2} \cdot V_{\mathrm{d}}\right) \\
P T S F_{3}=100 \cdot\left(1-\exp \left(a_{3} \cdot V_{\mathrm{d}}+b_{3} \cdot \sqrt{V_{\mathrm{o}}}\right)\right. \\
P T S F_{4}=a_{4} \cdot \ln \left(V_{\mathrm{d}}\right)+b_{4} \cdot \ln \left(V_{\mathrm{o}}\right)+c_{4} \cdot H V_{\mathrm{d}}+d_{4} \cdot \ln \left(V_{\mathrm{d}}\right) \cdot \ln \left(V_{\mathrm{o}}\right)+e_{4} \cdot \ln \left(V_{\mathrm{d}}\right) \cdot H V_{\mathrm{d}}
\end{gathered}
$$

where: 
- PTSF is the percent time spent following for base conditions (i.e. $0 \%$ no-passing zones; \%).

- $a_{\mathrm{i}}, b_{\mathrm{i}}, c_{\mathrm{i}}, d_{\mathrm{i}}$ and $e_{\mathrm{i}}$ are coefficients.

- Other terms are as previously defined.

The coefficients $a$ and $b$ were explicitly modelled, instead of breaking the sample into subsamples with similar opposing traffic flow, as in previous research $[2,16,17]$. The proposed approach would produce a model easier to apply (i.e. no interpolation from tables) and more robust (i.e. it was adjusted for the entire set of simulated cases).

Nonlinear and linear models were developed by using the NLS and MASS packages from the R statistical analysis software program respectively [30,31]. The logarithmic model [Equation (3d)] included all 32 possible combinations among five independent variables. AIC, correlation between fitted values and simulation values, beta parameters, $p$-value of the variables and number of parameters were then used to determine the best model for PTSF. A summary of the goodness of fit of the 52 models (20 nonlinear models and 32 linear models) is provided on the supporting information, as well as a statistical summary of the best model. Finally, the best model estimates were compared with the estimates from previous models on the literature.

\section{RESULTS AND DISCUSSION}

\subsection{ATS}

The best model for ATS was the HCM 2010 linear model considering directional traffic flow rate, opposing traffic flow rate and percent of heavy vehicles [Equation (4)]. The correlation between fitted and simulation values was $94 \%$.

$$
A T S=F F S-0.01504 \cdot V_{\mathrm{d}}-0.0064 \cdot V_{\mathrm{o}}-0.0522 \cdot H V_{\mathrm{d}}
$$

where:

- FFS is the free flow speed $(\mathrm{km} / \mathrm{h})$. In this case, the free flow speed was equal to $89.52 \mathrm{~km} / \mathrm{h}$.

- Other terms are as previously defined.

Figure 1 compares the simulation results and fitted values with Equation (4), depending on directional traffic flow and directional split. Even though the analysis was purely directional, the influence of opposing traffic flow varied depending on directional split. Directional split had a profound effect on ATS: A concave in shape speed-flow relationship would be preferable for less favourable directional splits (20/80-40/60), while a linear relationship could better capture ATS variation with directional traffic flow for more favourable directional splits (50/50-80/20). As expected, opposing traffic flow had a greater effect on ATS for directional splits below 40/60, producing a concave shape: For the same directional split, passing opportunities were reduced, and therefore ATS was lower. As the directional split became more favourable, passing restrictions due to opposing traffic flow decreased and ATS depended mainly on directional traffic flow. On the other hand, increasing the percentage of trucks reduced ATS, although this effect was lower than other traffic variables.

The model was compared with previous research. To facilitate the comparison, only directional splits of 30/70, 50/50 and 70/30 were plotted. Guidelines and simulation studies (Figure 2) were separated from field studies (Figure 3). The equations from previous research are summarized in Table I.

The HCM [2] estimates for ATS were the most accurate, after the proposed model [Equation (4); Figure 2]. The HCM generally underestimated ATS, and differences were greatest for the 30/70 directional split. On the one hand, the more aggressive driving behaviour in Spain (e.g., higher passing reconsideration probability) could cause the increase in ATS. On the other hand, providing different coefficients for directional and opposing traffic flow penalized ATS via less favourable directional splits. The German model [9] underestimated ATS for percentages of trucks higher than 20\%, and differences were higher for unbalanced flows. Considering only balanced flows in the LASI simulations produced an overestimation of opposing traffic flow effects on 70/30 directional splits, resulting in lower ATS. The model from Maldonado et al. [17] estimated ATS fairly well for the 70/30 


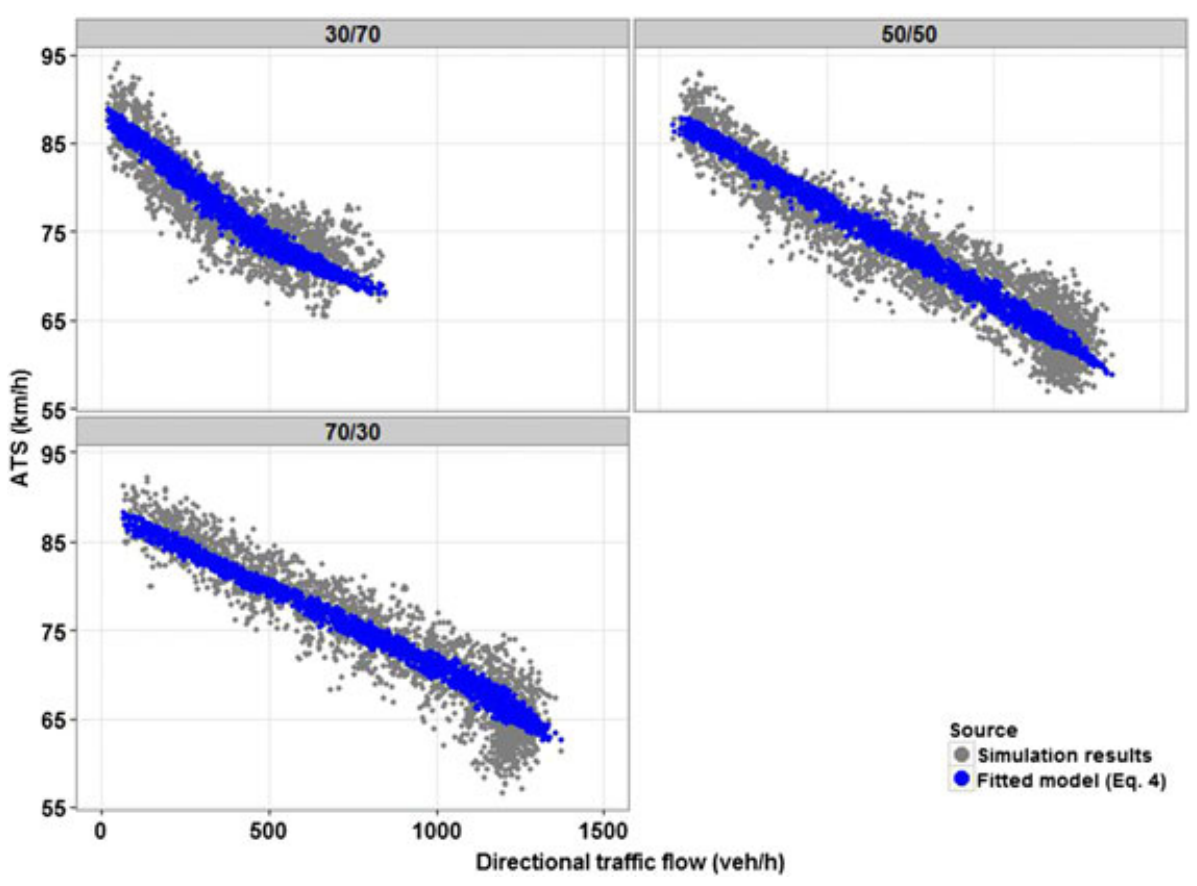

Figure 1. Average travel speed (ATS) for base conditions.

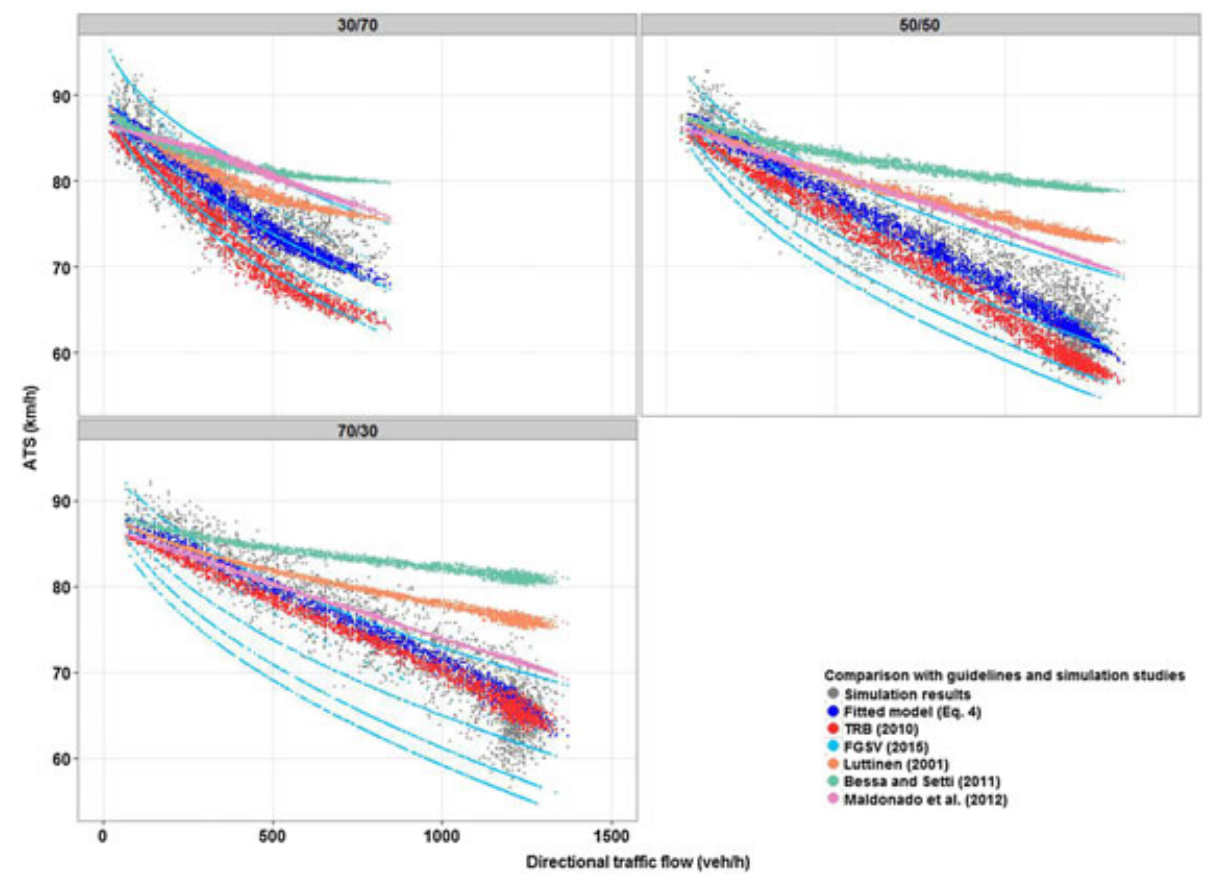

Figure 2. Discussion of ATS with guidelines and simulation studies.

directional split and overestimated ATS for the other directional splits. Differences between the TWOPAS passing model [5] and the CORSIM passing model [32] may cause higher ATS estimates from CORSIM with a higher presence of opposing vehicles. The models from Brazil [16] and Finland [15] overestimated ATS for all directional splits, and the differences increased as directional traffic flows increased. This was caused by the concavity of ATS, which did not allow higher decreases in ATS as directional traffic flows increased. 


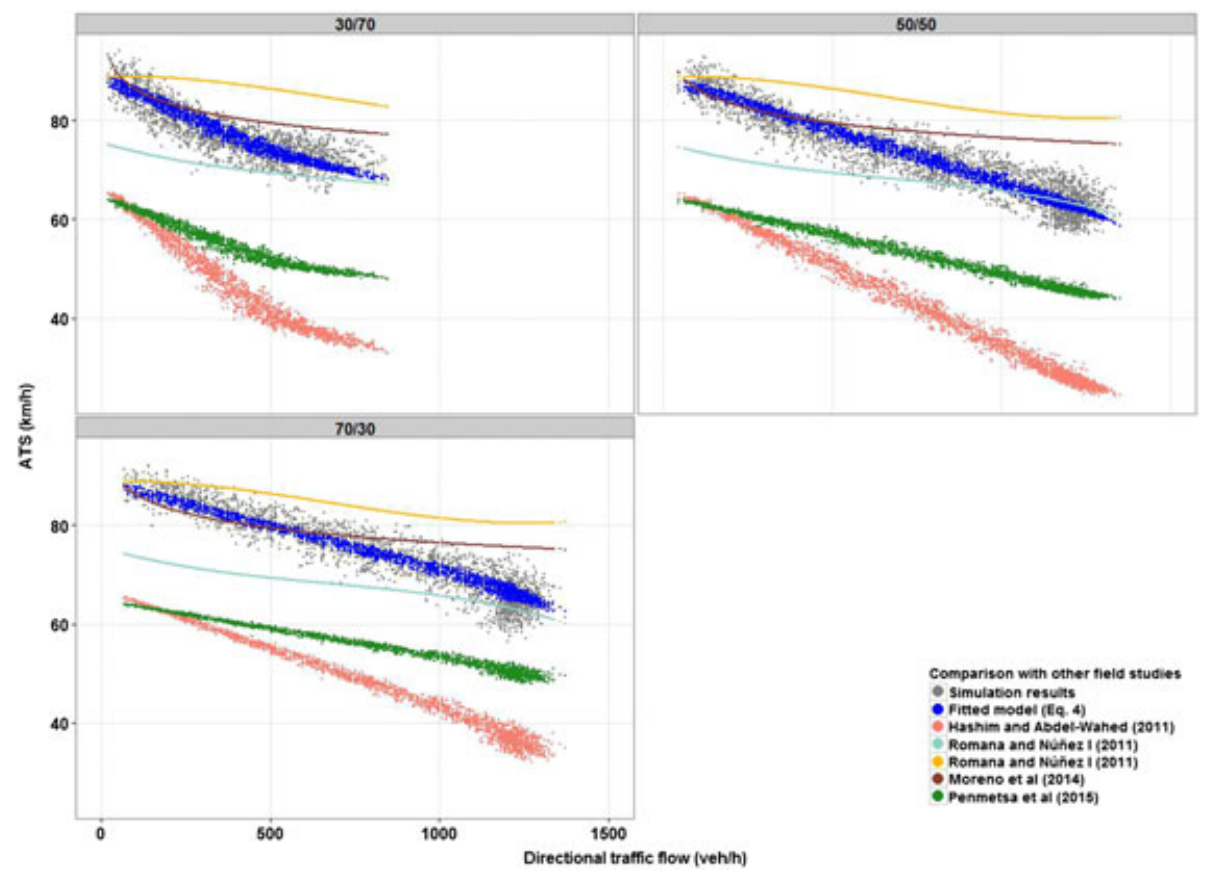

Figure 3. Discussion of ATS with other field studies.

As for the field studies, the model developed with the same field data [25] estimated ATS well for directional traffic flows lower than $500 \mathrm{veh} / \mathrm{h}$ (Figure 3). For higher directional traffic flows, the model overestimated ATS. On the other hand, the model developed from Spanish highway M305 predicted ATS fairly well under directional splits of 70/30, while the M509 highway model differed considerably due to its rolling terrain [24]. The models from Egypt [20] and India [26] underestimated ATS due to their lower posted speed limit $(60 \mathrm{~km} / \mathrm{h}$ in Egypt and $80 \mathrm{~km} / \mathrm{h}$ in India). Even though the posted speed limit in India was higher than in Egypt, free-flow speed was very similar $(64 \mathrm{~km} / \mathrm{h})$ due to mixed traffic conditions.

\subsection{PTSF}

The PTSF exponential model exhibited the strongest correlation to simulation results (97\%), pseudo $R^{2}$ (95\%) and minumum AIC [Equation (5)]. The correlation was 98\%, using the parameter descriptions shown in Equations (5a) and (5b).

$$
\begin{gathered}
\text { PTSF }=100 \cdot\left(1-\exp \left(a \cdot V_{\mathrm{d}}^{\mathrm{b}}\right)\right. \\
a=-2.12 \cdot 10^{-3}-3.48 \cdot 10^{-5} \cdot V_{\mathrm{o}}+6.15 \cdot 10^{-4} \cdot \ln \left(V_{\mathrm{o}}\right) \\
b=1.33-2.23 \cdot 10^{-5} \cdot V_{\mathrm{o}}-0.1 \cdot \ln \left(V_{\mathrm{o}}\right)
\end{gathered}
$$

where all terms are as previously defined.

Figure 4 compares the simulation results and the fitted model by using Equation (5). The model was adjusted to the average PTSF within simulation for directional splits 20/80-60/40. For higher directional splits (70/30-80/20), the model estimated the highest PTSF results. As observed, PTSF increased rapidly for directional splits 20/80-40/60. The increase was lower for directional splits $70 / 30-80 / 20$, becoming almost linear for $80 / 20$. The change on this relationship indicated the significant effect of directional split on PTSF. The proposed model [Equation (5)] could capture PTSF shape differences for all directional splits. 


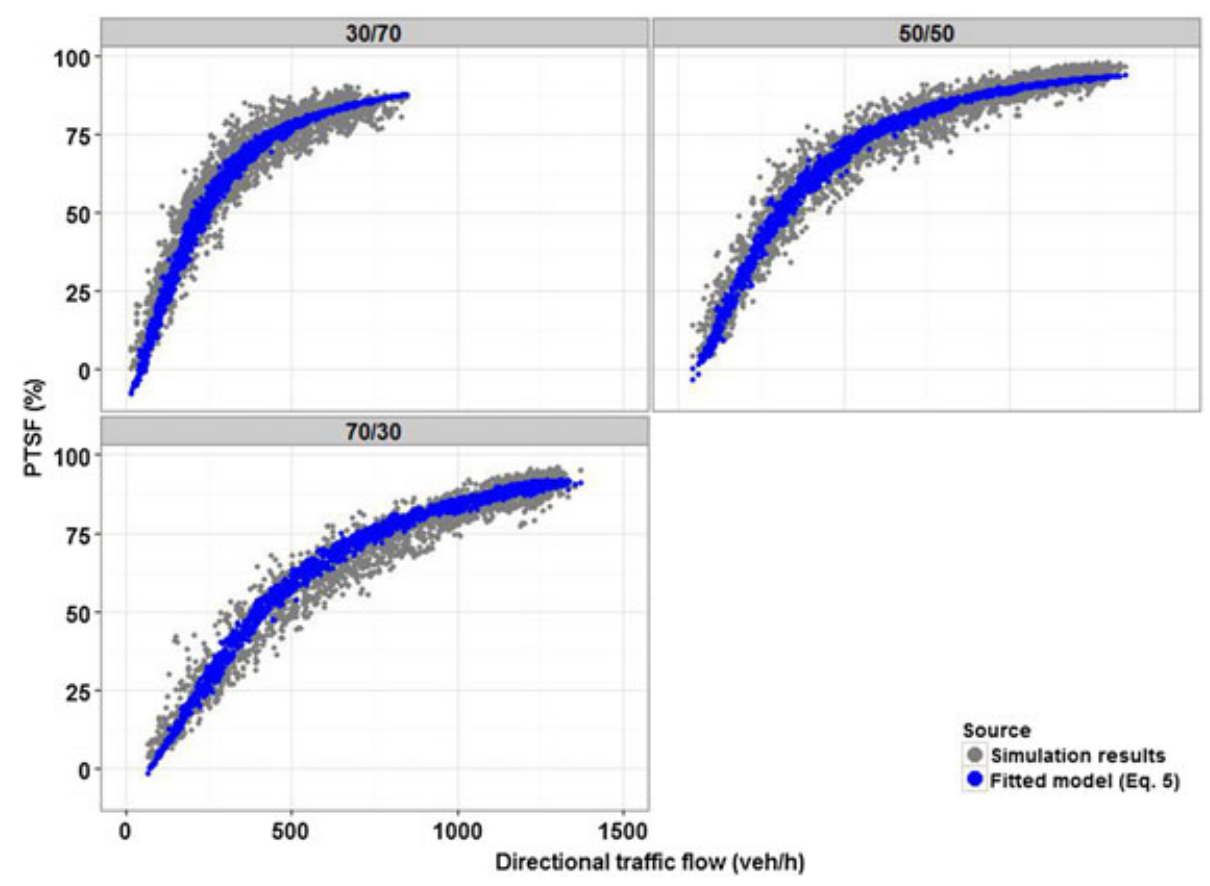

Figure 4. Per cent time spent following (PTSF) for base conditions.

The PTSF simulation results were compared with the PF simulation results, in order to verify if PF could be used as a surrogate of PTSF. In the simulations from Harwood et al. [3], the average value of PTSF was close to the average value of PF considering a headway equal to $3 \mathrm{~s}$, even though TWOPAS considers that a vehicle is following if the headway is less than $4 \mathrm{~s}$. In our study, the average PF was 40\% compared with PTSF's 73\%. Maximum values were also very different: 84 and 99\% respectively. The distribution of PF4 was closer to PTSF but had lower sensitivity to directional traffic flows. Consequently, PF was not completely related to PTSF and should be used as a surrogate measure for PTSF with caution.

The PTSF was also compared with international guidelines and microsimulation studies (Figure 5). Not surprisingly, the fitted model [Equation (5)] presented the lowest difference relative to the simulation results. The model from Bessa and Setti [16] was very close to the simulation results; PTSF was only overestimated for directional traffic flows lower than $200 \mathrm{veh} / \mathrm{h}$. The differences might be a consequence of different equations or driving behaviour, although both used TWOPAS and the same calibration technique. Similar to ATS, traffic performance was overestimated for non-balanced directional splits with the model from Maldonado et al. [17] due to differences in opposing traffic passing models between CORSIM and TWOPAS. The differences on ATS were significant, up to $25 \%$. A detailed calibration of the CORSIM passing model would reduce these differences. Surprisingly, the HCM model underestimated PTSF for almost all scenarios. For low traffic flows, the HCM overestimated PTSF by up to 20\%. As such, corrections recently included in the current HCM [2] to overcome PTSF overestimation might be too high [4]. The differences between PTSF and PF were substantial in TWOPAS, and adjusting PTSF to PF could lead to underestimation of PTSF.

Many of the previous field studies used linear relationships between PF and directional traffic flow [18-20, 23, 26], which caused significant differences between their estimates and the simulation results (Figure 6). The linear relationship may be true for low traffic flows; however, it fails to represent the rapid increase in PTSF for directional traffic flows starting around $400 \mathrm{veh} / \mathrm{h}$. The model from Romana and López [23] produced closer results, but it considers $4 \mathrm{~s}$ for the following condition and is linear. The logarithm model from the field study [25] produced fairly good PTSF estimates under low traffic flows and balanced flows, such as the field observations. On the other hand, the PTSF models proposed by Polus and Cohen [21] and Rozenshtein et al.[22] underestimated PTSF for all traffic conditions. 


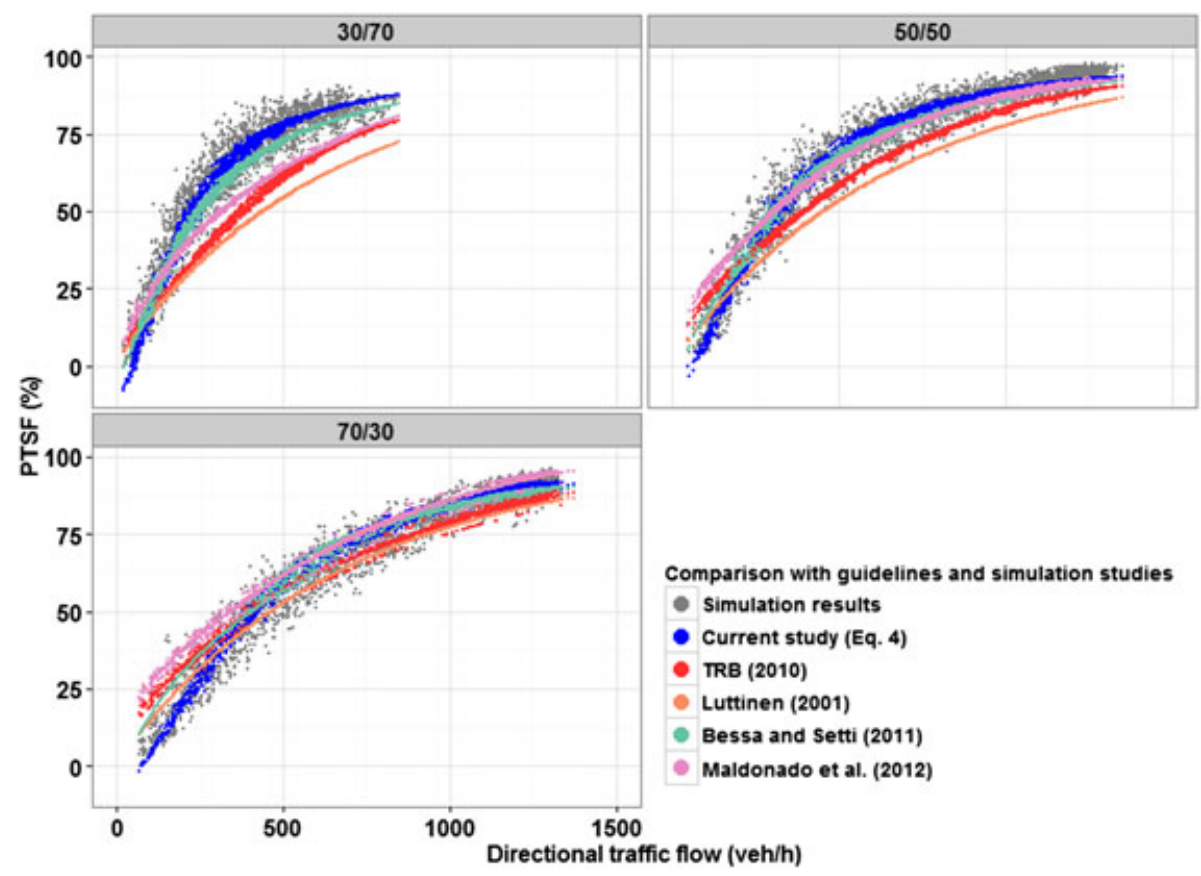

Figure 5. Discussion of PTSF with guidelines and simulation studies.

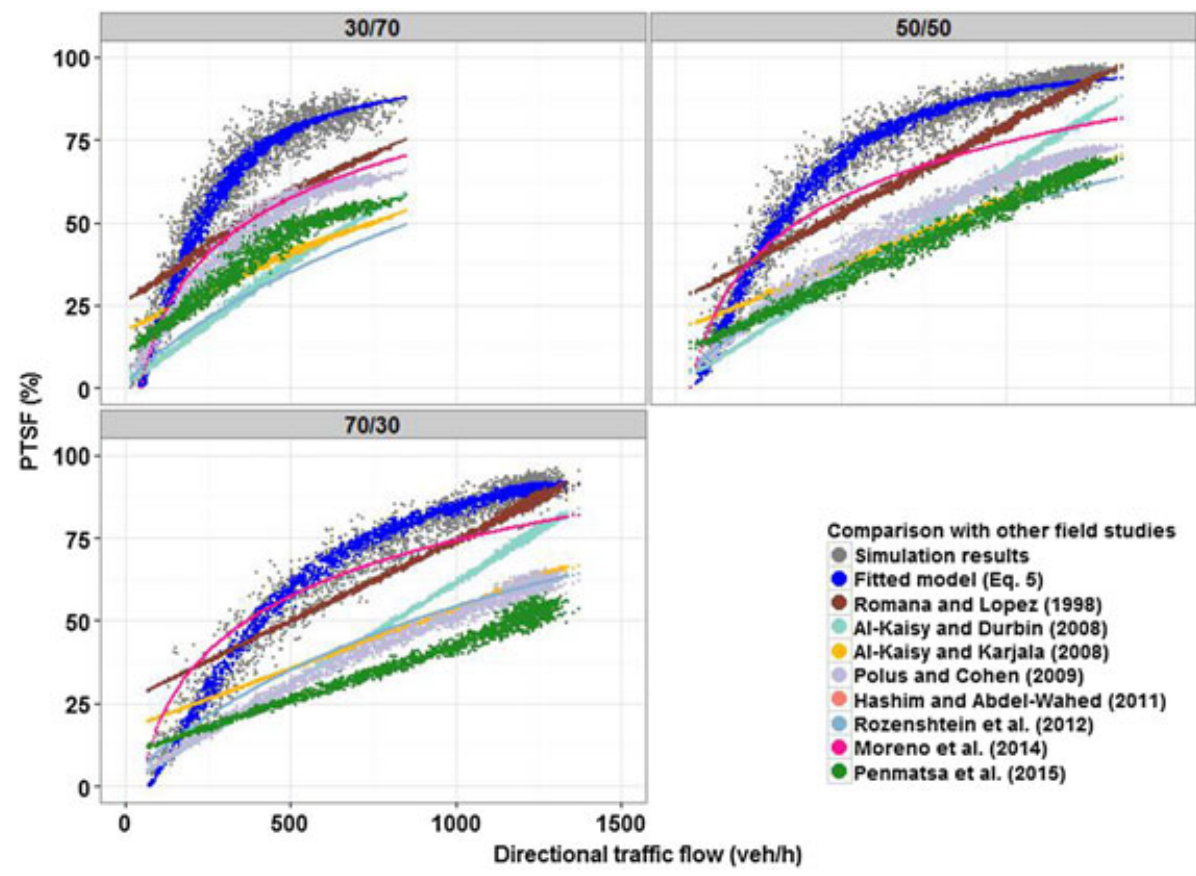

Figure 6. Discussion of PTSF with other field studies.

The difference may be caused by more aggressive driving behaviour in Israel or the theoretical approach used to develop their PTSF equation, which implied more aggressive driving behaviour (i.e. all drivers willing to pass when actual speed falls below desired speed).

\section{SUMMARY AND CONCLUSIONS}

This study has shown the adaptation of ATS and PTSF models to Spanish two-lane highways by using field data and traffic microsimulation in TWOPAS. Current passing behaviour was collected in passing 
zones with a posted speed limit of $100 \mathrm{~km} / \mathrm{h}$. TWOPAS was calibrated with a genetic algorithm. Then, it was applied to different scenarios varying directional traffic flow, directional split and percentage of heavy vehicles.

The conclusions of the study are:

- Directional split has a profound effect on traffic performance. Therefore, directional analysis is preferred and directional splits or opposing flows should be considered within the models.

- The ATS in base conditions depends on directional traffic flow, opposing traffic flow and percentage of heavy vehicles. The presence of heavy vehicles reduces ATS, but the effect is lower than directional traffic flow and directional split. ATS decreases linearly with directional traffic flow, similar to the HCM. However, the HCM underestimates ATS, which could be caused by Spain's aggressive driver behaviour.

- The PTSF in base conditions increases as directional flow increase. The model is the same as the HCM, although the influence of opposing traffic flow is explicitly modelled in the equation. Directional split can increase PTSF from 25 to $62 \%$ for the same directional traffic flow of $250 \mathrm{veh} / \mathrm{h}$. The HCM underestimates PTSF in almost all the Spanish conditions, except for low traffic flows.

- Adjustments for directional PTSF based on PF field data could lead to underestimation of PTSF due to significant differences between PTSF and PF distributions. A different criterion is used for classifying a follower in TWOPAS (4-s headway) and in the HCM (3-s headway).

Based on these conclusions, the recommendations of the study are:

- Application of HCM equations to the analysis of Spanish two-lane highways is not recommended. ATS and PTSF can be calculated by using Equations (4) and (5) respectively. This methodology is simpler than the HCM methodology and does not rely on interpolation from tables.

- The HCM-recommended 3-s headway could be used to calculate PF as a surrogate measure for PTSF, even though they are not completely related. Further study is needed to determine the most appropriate criteria for defining follower status, which may also include other factors beside headway, such as speed.

Conclusions of the study are limited to the observed and generated simulation scenarios: Spanish two-lane highways with $100 \mathrm{~km} / \mathrm{h}$ posted speed limit, level terrain, straight segments with very little passing restrictions and good pavement conditions. Other highways with higher presence of curves or considerable passing restrictions may need local adaptation. For those scenarios, passing restriction effects must be considered. Adjustment criteria from Moreno et al. [33] can be used.

\section{ACKNOWLEDGEMENTS}

The research was funded by the Spanish Ministry of Economy and Competitiveness (TRA201342578-P) and has been partially developed as a result of a mobility stay at the University of Florida funded by the Spanish Ministry of Economy and Competitiveness (EEBB-I-15-09970). The research was completed with the support of the FPI Research and Teaching Fellowship of the Spanish Ministry of Economy and Competitiveness (BES-2011-044612) and the TUM University Foundation Fellowship (TUFF) for international postdocs.

We would like to thank Dr Lemke from the Bundesanstalt für Straßenwesen (Federal Highway Research Institute) for providing the book from Brannolte and Holz [13] and the final reports of the research projects FE-Nr. 02.155G92 [12] and FE 16.0015/2009 [11].

The Spanish General Directorate of Traffic and Spanish Ministry of Public Works collaborated during the field study.

\section{LIST OF SYMBOLS AND ABBREVIATIONS}

The following symbols are used in this paper:

ATS average travel speed $(\mathrm{km} / \mathrm{h})$.

PTSF percent time spent following (\%).

Copyright @ 2016 John Wiley \& Sons, Ltd. 


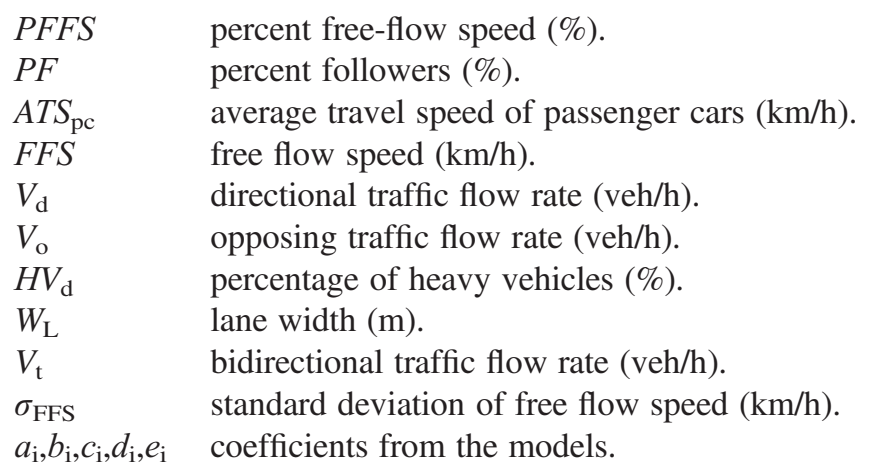

\section{REFERENCES}

1. Ministerio de Fomento. Instrucción de Carreteras 3.1 IC: Trazado. 1999.

2. Transportation Research Board. Highway Capacity Manual. Transportation Research Board, 2010.

3. Harwood DW, May AD, Anderson IB, Leiman L, Archilla AR. Capacity and quality of service of two-lane highways. NCHRP project 3-55. 1999.

4. Harwood DW, Potts IB, Bauer KM, Bonneson JA, Elefteriadou L. Two-lane road analysis methodology in the Highway Capacity Manual. NCHRP project 20-7. 2003.

5. Leiman L, Archilla AR May AD. TWOPAS Model ImprovementsCA: Berkeley, 1998.

6. Luttinen RT. Uncertainty in the operational analysis of two-lane highways. 2001.

7. Transportation Research Board. Highway Capacity Manual. 1985.

8. Transportation Research Board. Highway Capacity Manual. 2000.

9. Forschungsgesellschaft für Strassen und Verkehrswesen. Handbuch für die Bemessung von Strassenverkehrsanlagen (HBS edition 2015). 2015.

10. Brilon W, Weiser F. Two-lane rural highways: the German experience. Transportation Research Record: Journal of the Transportation Research Board 2006; 1988: 38-47. DOI:10.3141/1988-07.

11. Weiser F, Jäger S, Riedl C, Lohoff J. Verkehrstechnische Bemessung von Landstraßen - Weiterentwicklung der Verfahren. BASt-Bericht V 263. ISBN: 978-3-95606-197-4. 2016.

12. Brilon W, Weiser F. Ermittlung von Q-V-Diagrammen für zweistreifige Strassen ausserhald geschlossener Ortschaften. 1996.

13. Brannolte U, Holz S. Forschungsbericht "Simulation des Verkehrsablaufs aud Landstrassen Modellerweiterung”. Heft 402Forschung Strassenbau und Strassenverkehrstechnik: Bonn, Germany, 1983.

14. Luttinen RT. Percent time-spent-following as performance measure for two-lane highways. Transportation Research Record: Journal of the Transportation Research Board 2001; 1776: 52-59. DOI:10.3141/1776-07.

15. Luttinen RT. Level of service on Finnish two-lane highways. Transportation Research Circular E-C018: Fourth International Symposium on Highway Capacity 2000; E-C018: 175-187.

16. Bessa JEJ, Setti JR. Derivation of ATS and PTSF functions for two-lane, rural highways in Brazil. Procedia - Social and Behavioral Sciences 2011; 16: 282-292. DOI:10.1016/j.sbspro.2011.04.450.

17. Maldonado MO, Herz M Galarraga J. Modelación de operación en carreteras argentinas y recomendaciones de ajustes al Manual de Capacidad HCM 2010. Transportes 2012; 20(3): 51-61. DOI:10.4237/transportes.v20i3.556.

18. Al-Kaisy A, Karjala S. Indicators of performance on two-lane rural highways: empirical investigation. Transportation Research Record: Journal of the Transportation Research Board 2008; 2071: 87-97. DOI:10.3141/2071-11.

19. Al-Kaisy A, Durbin C. Evaluating new methodologies for estimating performance on two-lane highways. Canadian Journal of Civil Engineering 2008; 35(8): 777-785. DOI:10.1139/108-020.

20. Hashim IH, Abdel-Wahed TA. Evaluation of performance measures for rural two-lane roads in Egypt. Alexandria Engineering Journal 2011; 50(3): 245-255. DOI:10.1016/j.aej.2011.08.001.

21. Polus A, Cohen M. Theoretical and empirical relationships for the quality of flow and for a new level of service on two-lane highways. Journal of Transportation Engineering 2009; 135(6): 380-385. DOI:10.1061/(ASCE)0733947X(2009)135:6(380).

22. Rozenshtein S, Polus A Cohen M. Models for estimating drivers following on two-lane rural highways. Transportation Research Record: Journal of the Transportation Research Board 2012; 2286: 68-75.

23. Romana MG, López MG. Estimation of percentage of delayed vehicles based on traffic variables for rural highways. Transportation Research Record: Journal of the Transportation Research Board 1998; 1646: 29-36. DOI:10.3141/ 1646-04.

24. Romana MG, Núñez M. Proposal of an alternative model for speed-flow relationship in two-lane highways. Procedia - Social and Behavioral Sciences 2011; 16: 832-839. DOI:10.1016/j.sbspro.2011.04.502.

25. Moreno AT, Llorca C, Sayed T García A. Field evaluation of traffic performance measures for two-lane highways in Spain. Transportation Research Circular 2014; 190: 71-87. 
26. Penmetsa P, Ghosh I Chandra S. Evaluation of performance measures for two-lane intercity highways under mixed traffic conditions. Journal of Transportation Engineering 2015; 141(10): 1-7. DOI:10.1061/(ASCE)TE.19435436.0000787.

27. Luttinen RT. Uncertainty in operational analysis of two-lane highways. Transportation Research Record: Journal of the Transportation Research Board 2002; 1802: 105-114. DOI:10.3141/1802-13.

28. Moreno AT, Llorca C, García A Pérez-Zuriaga AM. Operational effectiveness of passing zones depending on their length and traffic volume. Transportation Research Record: Journal of the Transportation Research Board 2013; 2395: 57-65. DOI:10.3141/2395-07.

29. Al-Kaisy A, Karjala S. Car-following interaction and the definition of free-moving vehicles on two-lane rural highways. Journal of Transportation Engineering 2010; 136(10): 925-931. DOI:10.3141/2071-11.

30. Ripley B, Venables B, Bates DM, Hornik K, Gebhardt A, Firth D. Package MASS. https://cran.r-project.org/web/ packages/MASS/MASS.pdf [Apr. 25, 2016].

31. Baty F, Charles S Flandrois J-P. The R package nlstools : a toolbox for nonlinear regression. Journal of Statistical Software 2015; 66(5): 1-21. DOI:10.18637/jss.v066.i05.

32. Li J, Washburn SS. Implementing two-lane highway simulation modeling into CORSIM. Procedia - Social and Behavioral Sciences 2011; 16: 293-305. DOI:10.1016/j.sbspro.2011.04.451.

33. Moreno, A.T. Análisis de la funcionalidad del tráfico en carreteras convencionales en función de la distribución y características de sus zonas de adelantamiento [PhD Dissertation]. Ed. Universitat Politècnica de València 2015. DOI:10.4995/Thesis/10251/49618.

\section{SUPPORTING INFORMATION}

Additional supporting information may be found in the online version of this article at the publisher's web-site. 